\title{
PDCA APPLICATION AS A MANAGEMENT TOOL IN PROFESSIONAL QUALIFICATION COURSE
}

\author{
Marto Gibran Andrade Silva ${ }^{1}$ and David Barbosa de Alencar ${ }^{2}$
}

\begin{abstract}
${ }^{1}$ Blauro Cardoso de Mattos Higher Education Institute - FASERRA. Manaus-Amazonas, Brazil.
${ }^{2}$ Galileo Institute of Technology and Education of the Amazon - ITEGAM. Manaus-Amazonas, Brazil.
\end{abstract}

Email: marto_as@hotmail.com, david002870@hotmail.com

Received: Aug 09th, 2019

Accepted: Aug 30th 2019

Published: December 02 ${ }^{\text {th }}, 2019$

Copyright (02016 by authors and Galileo Institute of Technology and Education of the Amazon (ITEGAM).

This work is licensed under the Creative Commons Attribution International License (CC BY 4.0).

https://creativecommons.org/licen ses/by/4.0/

\begin{abstract}
Today we have several technological management tools, but still many projects or processes do not fit in any of them, the purpose is to report how simple, easy and effective to use the PDCA Cycle and help in decision making, guiding the path to improvement continuous management of processes or projects. The aim of this paper is also to elucidate the importance of the tool applied in the professional qualification course of Residential Hydraulic Installer of SENAI Demóstenes Travessa School, showing benefits in the acquisition of inputs and consequently lower financial expenses and environmental impacts.
\end{abstract}

Keywords: PDCA, Economics, Management, Application.

\section{INTRODUTION}

There is a clear need for planning around activities in any field of work, with a view to the continuous development, improvement or control of processes and products. Thus, the PDCA Cycle emerged in the 1920s, created by Walter A. Shewart, and spread by William Edward Deming from the 1950s in Japan, where it also became known as the "Deming Cycle".

The PDCA Cycle can be used within management system standards in any organization to ensure business success, regardless of area or department, and to achieve goals on an ongoing basis. The cycle is also comprehensive, as a device that can recognize new setbacks or progress with each cycle, always aiming at continuous improvement [1].

Planning is to predict the problems and cease them, in order to understand all the variables that may influence the desired results, but to adopt the present decisions to improve the future results [2].

The PDCA cycle of all management tools is one of the most widely applied in the world, to confront problems and extend the level of excellence in companies. Therefore, in this paper I will report what it is, what its use is and how the cycle can influence the results.
Contemporary time with the great competitiveness for space, companies need to innovate and adapt, introducing procedures to be able to produce more and better, investigating their weaknesses and strengths; they should also measure their performances, after all "what is not measured is not management" [3].

The purpose of the cycle [4] is to make the processes involved in the management execution clearer and more agile, indicating the causes of the problems and possible solutions to them, as well as assisting in the organization. It is divided into four stages: PLAN, DO, CHECK and ACT.

This work was developed with the objective of elucidating the applicability of the PDCA management tool and its respective importance, bringing benefits such as economy and lower environmental impacts when applied in the Residential Hydraulic Installer course at SENAI Demóstenes Travessa School, which is aimed at following the construction, and that follows the standards of the National Service of Industrial Learning - SENAI throughout Brazil.

\section{DEVELOPMENT}

A case study will be presented where I applied the PDCA tool, in order to have a continuous improvement, carried out at SENAI Demóstenes Travessa School, and aimed to reduce the 
waste of WELD PVC, SCREW PVC, SEW PVC, CPVC and PPR included in the practical classes of the professional qualification course of Residential Hydraulic Installer and consequently have a financial return for the institution, due to lower purchases of these inputs, as well as lower environmental impacts.

The teaching team that teaches the course embraced the implementation of the management tool facilitating the achievement of good results that will be presented in this work, helping to reduce waste without compromising the quality of learning of students, maintaining the same standard.

The tool was applied to the item pipes, one of the most expensive inputs and used in the Residential Hydraulic Installer course. The study and application of this tool can later also be implemented in other items or other professional qualification courses, mobilizing the importance of management and management.

The proposal to apply this management tool is also to show the importance and the advantages that it provides, through meetings, changes of customs and methods, discussed and evidenced in the planning phase of the PDCA tool, and can optimize a process if it impairs the development of the project even, bringing substantial benefits.

The results of the implementation of the PDCA tool conducted in the professional qualification course of Residential Hydraulic Installer at SENAI Demóstenes Travessa School were quantitative and collected data that will be presented below.

The objectives were planned in the class that started on May 17, 2019 and ended on June 28, 2019, and have already been applied to the subsequent class that started on June 17, 2019, in order to look for less waste and impacts emphasizing in the tube item, applied in the course practices.

PLAN Step: According to [5], planning means that managers think in advance about their actions and goals, and that their actions are based on some technique, plan or logic, not deductions.

To start the application of the PDCA methodology the problem / improvement was identified, which is the waste / disposal of pipes used in the Residential Hydraulic Installer course, with the goal of Reducing the Acquisition of Weldable PVC, Threadable PVC, Sewer PVC, CPVC and PPR per course started.

Faced with this obstacle, the goal was set to implement improvement, modifying some procedures that occurred during the course, such as waste management and reuse of pipes, creation of standard project in the practical class of pipe cutting, storage place of the pipes that will be reused, term and value.

It was analyzed during the course that began on May 2, 2019 and ended on June 28, for 15 students, the materials request worksheet requested by the teacher who used in practical classes. It requested 8 Weldable PVC pipes $25 \mathrm{~mm}, 8$ Weldable PVC pipes $32 \mathrm{~mm}, 6$ Threadable PVC pipes 3/4", 7 PVC pipes Sewer $40 \mathrm{~mm}$, 7 PVC pipes Sewer 50mm, 7 PVC pipes Sewer 75mm, 7 PVC pipes sewer $100 \mathrm{~mm}, 6 \mathrm{CPVC}$ pipes $22 \mathrm{~mm}$ and 7 PPR pipes $25 \mathrm{~mm}$ both 6 meters long.

It includes in the course lesson plan the practical execution of pipe cuts and installation of cold, hot water and sewage systems.

One of the first practical activities that the student develops is to make three cuts in each tube, in order to qualify them in this procedure, the measure was defined by the teacher, who requested $30 \mathrm{~cm}$ cuts.

After the student knows the entire process of residential plumbing, the last activity is the execution of a cold, hot and sewage system project where he reads an already standard floor plan and executes, and for these projects the pipes Most of them are over 1 meter long.
Immediately after each execution of the requested tasks, the systems are disassembled and the tubes are disposed of at a separate collection site.

At this collection site I observed several tubes in which they could be reused in practical cutting classes, avoiding acquisitions / expenses and reducing environmental impacts.

It was also analyzed with the faculty that teaches this course, the possibility of creating a cutting project, standardizing this process, determining smaller gauges in order to reuse the tubes of the final projects discarded by the previous class.

The planning was made to be implemented and applied in the next classes, having an immediate deadline in order to bring an economy in this input.

Step DO: As planned, tubes with gauges larger than $30 \mathrm{~cm}$ that had already been discarded were selected to be reused, creating a place inside the hydraulic laboratory for storage, as shown in figure 1.

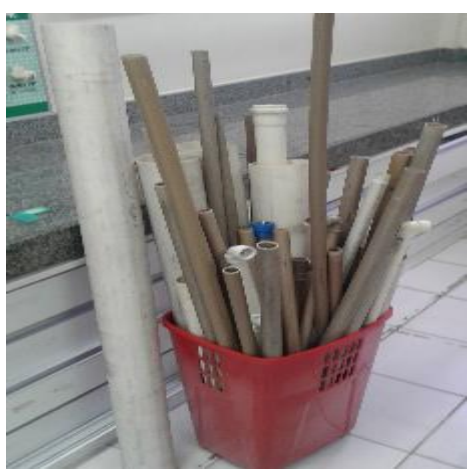

Figure 1: Part of the tubes selected for reuse. Source: Authors, (2019).

We also standardized the practice of pipe cutting with a design, as shown below, already implemented in the later class. We observed a reduction in the consumption of tubes pertinent to the students' practices, consequently saving and lower environmental impacts.

CHECK step: With the selection of tubes larger than $30 \mathrm{~cm}$ that would be discarded by the previous class, we reused and applied to the posterior class in the tube cutting practices, shown in figure 2, already using the standard cutting design, thus avoiding purchases and tube cuts in which it was stored in a location within the hydraulic laboratory.

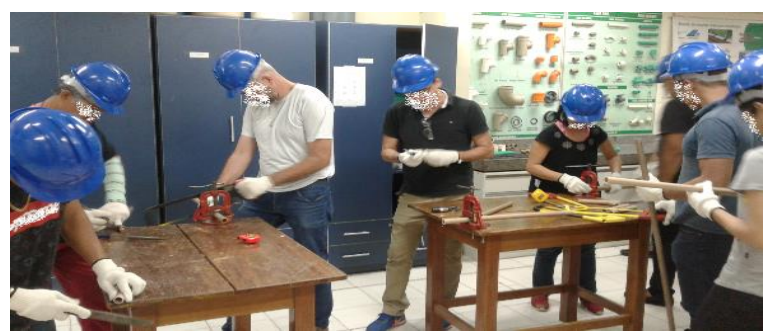

Figure 2: Students reusing the pipes in the practice of cutting. Source: Authors, (2019).

ACT Step: In the class that starts the PDCA cycle, the implementation of the tool was planned, the student requested for the practical classes 63 tubes, totaling an estimated total cost of $\mathrm{R} \$ 3534.56$.

The faculty worked together in a disciplined manner, applying the PDCA tool, to make the necessary changes outlined in the plan step, succeeding in its first implementation, and ready to start a new cycle while maintaining or improving results. 
We can observe that it was no longer using 18 tubes, maintaining the same practices and characteristics, without the tubes used, about $\mathrm{R} \$ 1033.64$, according to TABLE 1. harming the quality of the course, obtaining a savings of $29.25 \%$ in

Table 1: Pipe acquisition chart before PDCA tool implementation.

\begin{tabular}{|c|c|c|c|c|c|}
\hline $\begin{array}{c}\text { First Class: Before } \\
\text { Implementing PDCA }\end{array}$ & $\begin{array}{c}\text { Tube } \\
\text { Quantities } \\
\text { :Cutting } \\
\text { Practice }\end{array}$ & $\begin{array}{c}\text { Tube Quantities: Cold } \\
\text { and Hot Water } \\
\text { System Assembly } \\
\text { Practice }\end{array}$ & $\begin{array}{c}\text { Total } \\
\text { Tubes: By } \\
\text { Type. }\end{array}$ & $\begin{array}{c}\text { Unitary } \\
\text { value }\end{array}$ & $\begin{array}{c}\text { Total Amount: } \\
\text { Per Tube }\end{array}$ \\
\hline Weldable PVC Pipe 25mm & 3 & 5 & 8 & $\mathrm{R} \$ 16,99$ & $\mathrm{R} \$ 135,92$ \\
\hline Weldable PVC Pipe 32mm & 3 & 5 & 8 & $\mathrm{R} \$ 48,52$ & $\mathrm{R} \$ 388,16$ \\
\hline 3/4"Threaded PVC Pipe & 3 & 3 & 6 & $\mathrm{R} \$ 68,89$ & $\mathrm{R} \$ 413,34$ \\
\hline PVC Sewer Pipe 40mm & 3 & 4 & 7 & $\mathrm{R} \$ 34,87$ & $\mathrm{R} \$ 244,09$ \\
\hline PVC Sewer Pipe 50mm & 3 & 4 & 7 & $\mathrm{R} \$ 59,56$ & $\mathrm{R} \$ 416,92$ \\
\hline PVC Sewer Pipe 75mm & 3 & 4 & 7 & $\mathrm{R} \$ 65,49$ & $\mathrm{R} \$ 458,43$ \\
\hline PVC Sewer Pipe 100mm & 3 & 4 & 7 & $\mathrm{R} \$ 76,90$ & $\mathrm{R} \$ 538,30$ \\
\hline CPVC 22mm Tube & 3 & 3 & 7 & $\mathrm{R} \$ 79,80$ & $\mathrm{R} \$ 478,80$ \\
\hline PPR 25mm Tube & 3 & 4 & 63 & $\mathrm{Custos}$ & $\mathrm{R} \$ 460,60$ \\
\hline
\end{tabular}

Source: Authors, (2019).

Once planned, the goals were put into practice by separating the tubes for reuse, creating a deposit site within the hydraulics lab, standardizing a cutting design, and aligning all information with students who teach the same course. With this, we get a positive result, ready to restart a new PDCA cycle, ensuring uninterrupted improvement.
The analysis below shows the reduction in the purchase of new tubes, requested by the student in the bill of materials, from 63 to 45 tubes used in practical classes, obtaining a difference of 18 tubes considering an estimated cost reduction of $\mathrm{R} \$ 3534.56$ to $\mathrm{R} \$$ 2500.92, about 29.24\% less, as shown in TABLE 2 and shown in Figure 3.

Table 2: Pipe acquisition chart after PDCA tool implementation.

\begin{tabular}{|c|c|c|c|c|c|}
\hline $\begin{array}{c}\text { First Class: Before } \\
\text { Implementing PDCA }\end{array}$ & $\begin{array}{c}\text { Tube } \\
\text { Quantities: } \\
\text { Cutting } \\
\text { Practice }\end{array}$ & $\begin{array}{c}\text { Tube Quantities: } \\
\text { Cold and Hot Water } \\
\text { System Assembly } \\
\text { Practice }\end{array}$ & $\begin{array}{c}\text { Total } \\
\text { Tubes: By } \\
\text { Type. }\end{array}$ & $\begin{array}{c}\text { Unitary } \\
\text { value }\end{array}$ & $\begin{array}{c}\text { Total Amount: } \\
\text { Per Tube }\end{array}$ \\
\hline Weldable PVC Pipe 25mm & 1 & 5 & 6 & $\mathrm{R} \$ 16,99$ & $\mathrm{R} \$ 101,94$ \\
\hline Weldable PVC Pipe 32mm & 1 & 5 & 6 & $\mathrm{R} \$ 48,52$ & $\mathrm{R} \$ 291,12$ \\
\hline 3/4"Threaded PVC Pipe & 1 & 3 & 4 & $\mathrm{R} \$ 68,89$ & $\mathrm{R} \$ 275,56$ \\
\hline PVC Sewer Pipe 40mm & 1 & 4 & 5 & $\mathrm{R} \$ 34,87$ & $\mathrm{R} \$ 174,35$ \\
\hline PVC Sewer Pipe 50mm & 1 & 4 & 5 & $\mathrm{R} \$ 59,56$ & $\mathrm{R} \$ 297,80$ \\
\hline PVC Sewer Pipe 75mm & 1 & 4 & 5 & $\mathrm{R} \$ 65,49$ & $\mathrm{R} \$ 327,45$ \\
\hline PVC Sewer Pipe 100mm & 1 & 4 & 5 & $\mathrm{R} \$ 76,90$ & $\mathrm{R} \$ 384,50$ \\
\hline CPVC 22mm Tube & 1 & 3 & 4 & $\mathrm{R} \$ 79,80$ & $\mathrm{R} \$ 319,20$ \\
\hline PPR 25mm Tube & 1 & 4 & 5 & $\mathrm{R} \$ 65,80$ & $\mathrm{R} \$ 329,00$ \\
\hline
\end{tabular}

Source: Authors, (2019).

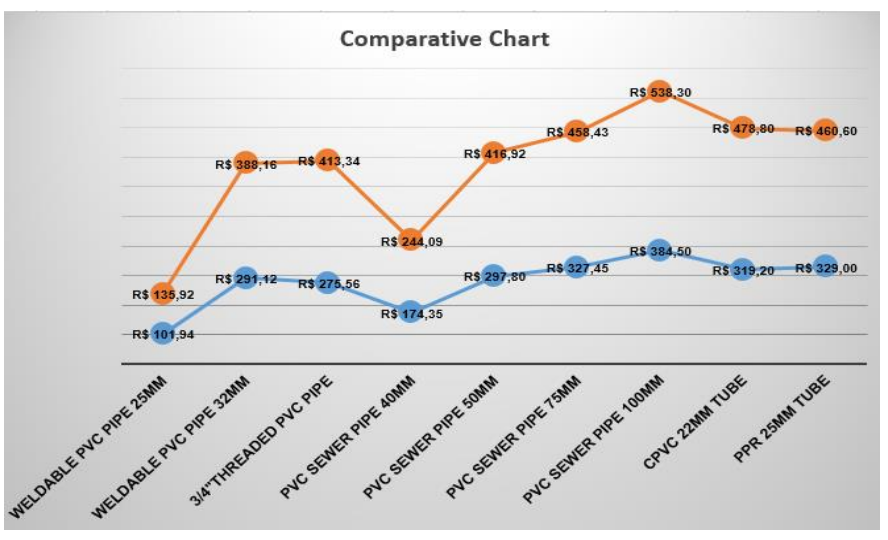

Figure 3: Comparative graph of spending. Source: Authors, (2019).
Given the implementation of this PDCA management tool within the professional qualification course, we had an optimization of the pipe item consumption process, bringing financial benefits and lower environmental impacts.

\section{CONCLUSIONS}

It was important to note that at the end of the PDCA Cycle, it must be restarted to ensure uninterrupted improvement of the processes or services to which the tool was applied, taking full advantage of the tool, bearing in mind that this process can be redone as often as necessary, focusing on a single process or others in a given activity, seeking optimization, since their information is cumulative, emphasizing that the cycle is a continuous process. 
Tool phases must be constantly evolving and should not be left behind. Only then will the process and activity improvements be visible to everyone, bringing the expected results.

Thus, PDCA cycle shows in the strategic management of companies its greatest application potential, because the tool works on the day-to-day problems through the use of all the inherent solutions to the method, the problems that damage the companies survival are pointed out, prioritized by their level of value and the negative impact it has on the business, where they will be dealt with effectively, with actions that will block the negative causes raised, improving the next service or production cycle, bringing satisfaction to all.

\section{ACKNOWLEDGMENTS}

I thank my God with your Grace, all my relatives, especially my parents and sisters who have contributed in some way throughout this journey with their affection, encouragement and support.

I thank all the people who contributed in some way to the development and realization of this work, especially the coordination of the SENAI Demóstenes Travessa School and the Braulio Cardoso de Mattos Educational Institution - FASERRA.

\section{REFERENCES}

[1] Francisco, L. L. Why quality management tools and methods are important to the company. Administrators Portal, 2011.

[2] Correa, H. L; Caon, M; Gianesi, I.G.N. Production planning, scheduling and control. São Paulo, Atlas, 2007.

[3] Kaplan, R. S.; Norton, D. P. The strategy in action: balanced scorecard. Rio de Janeiro: Campus, 1997.

[4] PDCA cycle. Available at:

<https://en.wikipedia.org/wiki/PDCA> Accessed 12/07/2019.

[5] Oliveira, J. F. de; Silva, E. A. da. Organizational management: Discovering a key to success for business. São Paulo: Saraiva, 2006. 